\title{
REVISIÓN DE LITERATURA
}

\section{FITOTERAPIA EN EMBARAZO Y LACTANCIA: ¿BENEFICIO 0 RI ESGO?}

\section{PHYTOTERAPY IN PREGNANCY AND LACTATION: BENEFIT OR RISK?}

REVI EW OF THE LITERATURE

Autores:

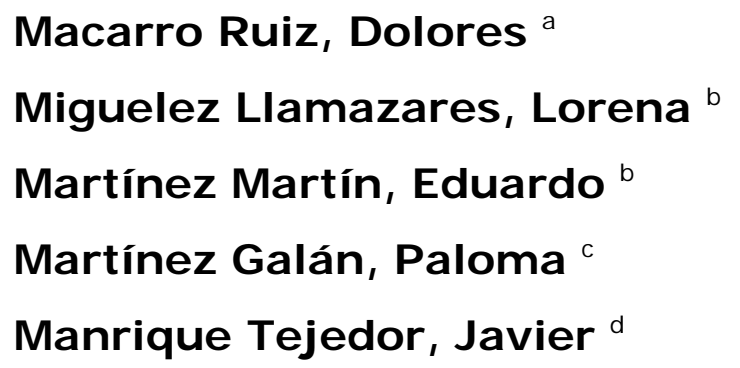

a Servicio de Paritorio. Hospital Don Benito - Villanueva. Extremadura.

b Servicio de Paritorio. Hospital General de Segovia.

c Servicio de Paritorio. Hospital Virgen de la Salud. Toledo.

d Servicio de Paritorio. Hospital Universitario Arnau de Vilanova. Lleida.

Correspondencia: lola_maca@hotmail.com 


\section{RESUMEN}

\section{Tí TULO}

Fitoterapia en embarazo y lactancia: ¿beneficio o riesgo? Revisión de literatura.

\section{NTRODUCCIÓN}

Durante el embarazo el organismo de la mujer sufre cambios temporales con aparición de estructuras orgánicas nuevas como la placenta. Cualquier sustancia, natural o sintética, que pueda producir una alteración de los procesos fisiológicos propios de esta etapa están contraindicados.

\section{OBJ ETIVO}

Dar a conocer los productos de origen vegetal utilizados habitualmente en el embarazo y la lactancia y evaluar su eficacia y seguridad.

\section{MATERI AL Y MÉTODOS}

Revisión integradora de la literatura en las bases de datos Cochrane Library, Cinahl, Medline, Cuiden, Cuidatge, Bireme, Enfispo y buscadores de la red. Tras la lectura de los artículos, se realizó una valoración crítica, síntesis e interpretación para llegar a conclusiones de todos los estudios seleccionados.

\section{RESULTADOS}

El uso de plantas medicinales en el embarazo es habitual, encontrándose el jengibre y la equinácea entre las más utilizadas. En cuanto a la etapa del embarazo de mayor consumo, se identifica el primer trimestre. El mayor porcentaje de las gestantes utiliza las plantas sin indicación médica.

En cuanto a la eficacia: la equinácea es eficaz para el resfriado común e infecciones vaginales, el arándano rojo para la infección urinaria, la raíz de jengibre y la ipecacuana tienen acción antiemética, la hierba de San Juan es eficaz en la depresión postparto, la valeriana para combatir el nerviosismo y el aceite de onagra para inducir el parto.

El nivel de seguridad varía según la planta por lo que se recomienda un control por parte del profesional sanitario. 


\section{SCUSI ÓN Y CONCLUSIONES}

De forma general las mujeres no están educadas en cuanto a la influencia que ejerce el estilo de vida en las primeras células embrionarias.

El uso de productos fitoterápicos puede ser eficaz para ayudar a solucionar muchos de los problemas del embarazo pero es necesario ver la relación riesgo-efectividad. Por eso, antes, durante y después del embarazo o lactancia materna las mujeres que desean tomar preparados herbarios, deben consultar con su matrona u otro profesional sanitario bien informado al respecto, porque muchos de los efectos de las plantas sobre los fetos y la leche materna son desconocidos.

\section{PALABRAS CLAVES}

terapias alternativas, fitoterapia, homeopatía, productos herbals, esencias florales, flores de Bach, enfermería, matrona, embarazo.

\section{ABSTRACT}

TI TLE

Pphytoterapy in pregnancy and lactation: benefit or risk? Rreview of the literature.

\section{NTRODUCTI ON}

During pregnancy, women's body suffers from temporary changes with new organic structures such as placenta. Any subtance, natural or sintetic which may alter physiological proceses on this own state are contraindicated.

\section{OBJ ECTI VE}

Dara know the plant products commonly used in pregnancy and lactation and assess their effectiveness and safety.

\section{MATERI AL AND METHODS}

Integrative review of literature in the databases Cochrane Library, CINAHL, Medline, Cuiden, Cuidatge, Medicine, ENFISPO and Web searches. 
After reading the articles, critical appraisal, synthesis and interpretation was performed to reach conclusions of all selected studies.

\section{RESULTS}

The use of medicinal plants during pregnancy is frequent, being ginger and echinace some of the most used ones.

Regarding the stage of pregnancy with higher consumption, it is the first term. The highest percentage of pregnant women use plants without any medical advices.

As for effectiveness: Echinacea is effective for the common cold and vaginal infections, cranberry for urinary infection, ginger root and ipecac have antiemetic action, St. John's wort is effective in postpartum depression, valerian to combat nervousness and evening primrose oil to induce labor.

The security level varies depending on the plant so a control by the health care professional is recommended.

\section{SCUSI ON AND CONCLUSI ONS}

Generally, women are not aware of the influence of their life style on the fist embryonic cells.

The use of herbal products can be effective in helping to solve many of the problems of pregnancy but you need to see the risk-effectiveness. Because of that, previously, during an after pregnancy or breastfeeding, those women who want to take herbolist products, should first consult a midwife or another medical professional who is well-informed about it, because many of the effect of plants on fetus and breastmilk are still unknown.

\section{KEY WORDS}

alternative therapies, phytotherapy, homeopathy, herbal agents, herbal products, floral esencies, bach flowers, nursing, midwife, pregnancy. 


\section{NTRODUCCI ÓN:}

La Fitoterapia, del griego Phytos (planta) se define como la ciencia que estudia la utilización de los productos de origen vegetal con finalidad terapéutica, ya sea para prevenir, atenuar o curar un estado patológico ${ }^{1}$.

Dioscórides (50 d.C.) médico de la legión romana, describe en su libro “De materia médica”, 950 sustancias curativas, de las cuales 600 son productos vegetales y fue usado como guía médica por el mundo romano y árabe, estando en vigor hasta la Edad Media. En dicha obra encontramos productos utilizados en la lactancia (mastitis, destete, relactación). De sus aportaciones aún pueden verse ejemplos en la zona mediterránea, Asia, África y las Américas ${ }^{2,3,4}$.

Las comadronas de la antigua Grecia empleaban el cornezuelo de centeno, utilizado actualmente para el tratamiento de las hemorragias postparto ${ }^{5}$. Sorano, médico romano del siglo II, afirmaba que la partera tenía que ser experta en la administración de prescripciones dietéticas y farmacológicas ${ }^{6}$. Los textos ofrecían un amplio arsenal de sustancias de herboristería encaminadas a favorecer la dilatación cervical, administradas bajo diferentes formas como infusiones, fomentos, sahumerios, baños de vapor, pesarios vaginales y emplastos en la zona lumbar, ingles, muslos, ombligo y pubis de la parturienta ${ }^{7}$. Paracelso fue el primero en señalar que las propiedades medicinales de las plantas radican en sus principios activos ${ }^{8}$.

Edward Bach (1886-1936), padre de la medicina floral, comprobó que gran parte de las enfermedades que presentaban sus pacientes tenían estrecha vinculación con la personalidad de cada uno de ellos y se interesó por hallar la raíz de los conflictos como el camino para recuperar la armonía general y, así colaborar con la salud mental o física9.

La medicina floral o antroterapia se refiere a un método terapéutico alternativo y natural basado, en su mayoría, en esencias extraídas de flores silvestres ${ }^{10}$.

Desde hace aproximadamente dos décadas se ha observado un especial interés por el empleo de plantas medicinales en los países occidentales.

La Comisión de la Unión Europea (UE) recomienda desde el año 2003, 
que las matronas den consejo a las mujeres embarazadas sobre el uso de suplementos alimenticios (vitaminas y minerales) y suplementos de herboristería (fitoterapia, homeopatía y aromaterapia) ${ }^{11}$

Durante el embarazo el organismo de la mujer sufre cambios temporales con aparición de estructuras orgánicas nuevas como la placenta. Cualquier sustancia, natural o sintética, que pueda producir una alteración de los procesos fisiológicos propios de esta etapa están contraindicados. Para la mayoría de las drogas vegetales más que una contraindicación directa se aconseja su empleo bajo supervisión médica.

La lactancia también es un periodo especial en la que algunas drogas vegetales están contraindicadas, dado que los principios activos o sus metabolitos pueden pasar a la leche y al lactante, e incluso producir un sabor amargo desagradable en la leche materna que provoque el rechazo del lactante ${ }^{12}$.

El objetivo de esta revisión literaria, es dar a conocer qué productos de origen vegetal son mas utilizados habitualmente en el embarazo y la lactancia, así como evaluar su eficacia y seguridad para proporcionar unas herramientas adecuadas al profesional sanitario y éste pueda dar una información correcta a las mujeres que nos demandan información acerca de los productos existentes en el mercado.

\section{MATERI AL Y MÉTODOS}

Para la realización de esta trabajo se lleva a cabo una revisión narrativa de la literatura relacionada sobre los aspectos más importantes en relación con el consumo de productos de fitoterapia, así como de la seguridad y utilidad de los mismos (Tabla 1). Las bases de datos consultadas fueron Cochrane Library, Cinahl, Medline, Cuiden, Cuidatge, Bireme, Enfispo y buscadores de la red, en castellano y en inglés, sin límite de años, incluyendo estudios originales publicados hasta la actualidad. Las palabras clave usadas fueron: terapias alternativas, fitoterapia, homeopatía, productos herbales, esencias florales, flores de Bach, enfermería, matrona, embarazo. A partir de su análisis se seleccionaron aquellos artículos originales y revisiones bibliográficas siguiendo 
como criterios de relevancia y actualidad del tema que nos compete (Tabla 2). El principal motivo de exclusión de los artículos fue el no estar directamente relacionados con el tema de nuestra revisión.

TABLA 1.-Clasificación de los niveles de riesgo. ${ }^{13}$

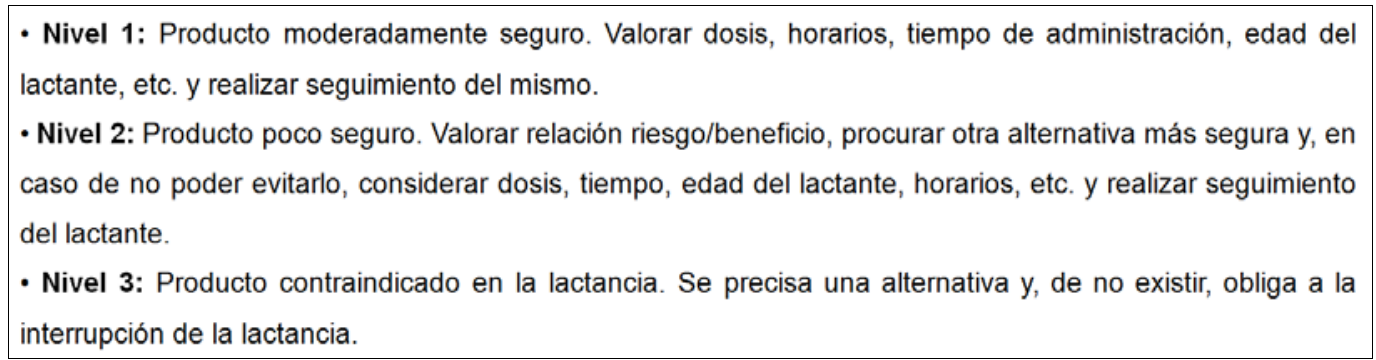

TABLA 2.- Artículos incluidos en la presente revisión.

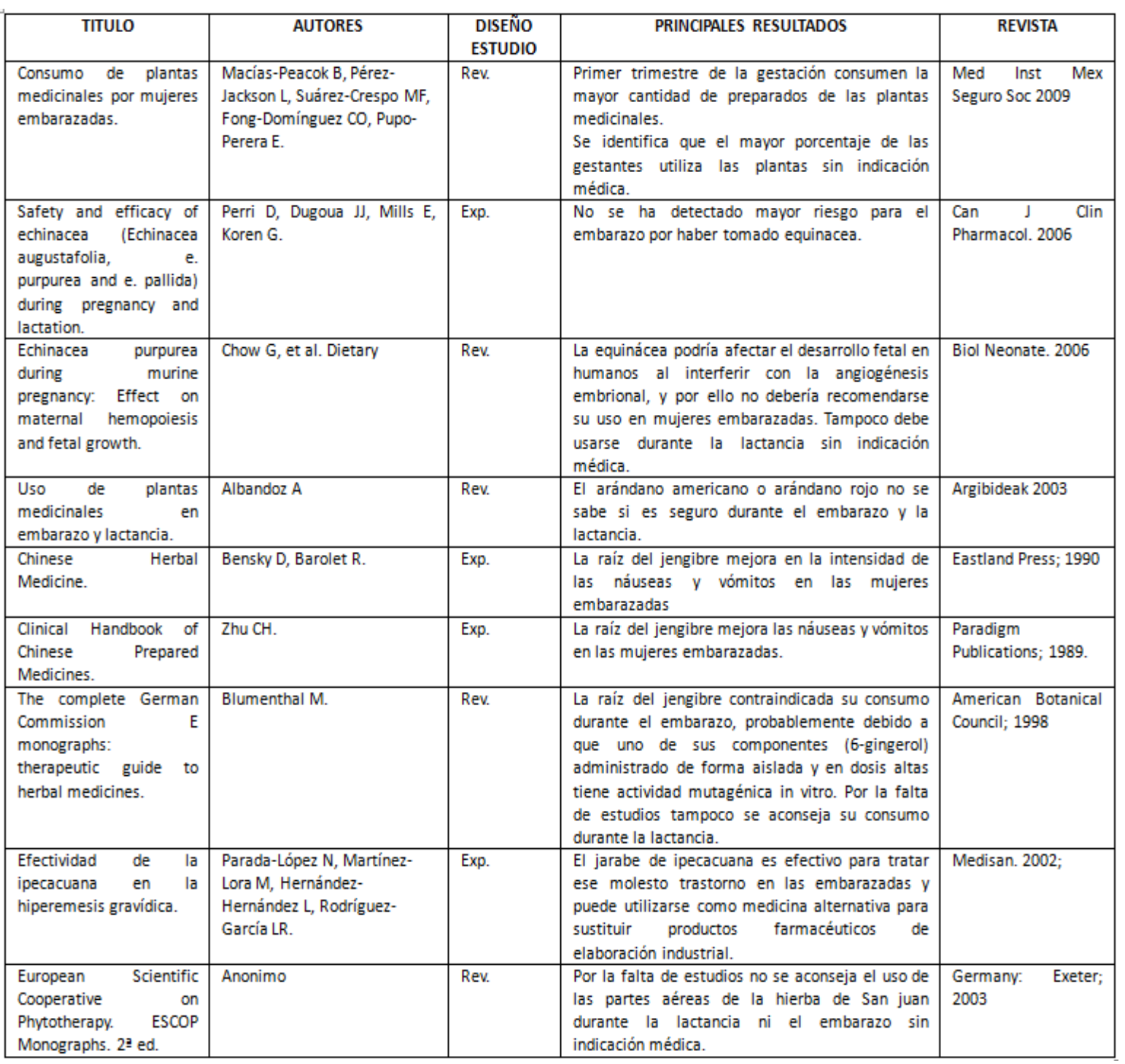




\begin{tabular}{|c|c|c|c|c|}
\hline $\begin{array}{lr}\text { Uso de } & \text { plantas } \\
\text { medicinales } & \text { en } \\
\text { embarazo y lactancia. }\end{array}$ & Albandoz A, et & Rev. & $\begin{array}{l}\text { La raiz de Valeriana produce retraso en la } \\
\text { osificación y cierto potencial mutagénico y } \\
\text { citotóxico. Por la falta de estudios no debería } \\
\text { usarse durante el embarazo y lactancia sin } \\
\text { indicación médica y solo se acepta su uso en } \\
\text { caso de ausencia de alternativas terapéuticas } \\
\text { más seguras bajo prescripción y control médico. }\end{array}$ & Argibideak 2003 \\
\hline $\begin{array}{lr}\text { Uso de } & \text { plantas } \\
\text { medicinales } & \text { en } \\
\text { embarazo y lactancia. }\end{array}$ & Albandoz A, et & Rev. & $\begin{array}{l}\text { El aceite de onagra en las últimas semanas de } \\
\text { gestación para inducir el parto es } \\
\text { extremadamente habitual. No se han notificado } \\
\text { eventos adversos en el feto. Solo debe usarse } \\
\text { por indicación médica. La administración a } \\
\text { madres lactantes durante } 8 \text { meses, la lactancia, } \\
\text { condujo a una mayor concentración de ácidos } \\
\text { grasos esenciales. }\end{array}$ & Argibideak 2003 \\
\hline $\begin{array}{l}\text { Risk assessment for } \\
\text { Senna during pregnancy. }\end{array}$ & Anonimo & Rev. & $\begin{array}{l}\text { El SEN ha sido señalado como seguro en el } 29 \text { y } \\
39 \text { trimestre de embarazo, y se ha visto que en } \\
\text { esta etapa, los beneficios superan en gran } \\
\text { medida a los riesgos. }\end{array}$ & Pharmacology. 1992 \\
\hline $\begin{array}{l}\text { Uso del sen durante el } \\
\text { embarazo y lactancia }\end{array}$ & $\begin{array}{l}\text { Morales MA, Diaz J, } \\
\text { Barrientos C, Bachiller LI, } \\
\text { Figueroa H. }\end{array}$ & Rev. & $\begin{array}{l}\text { El SEN tiene un buen efecto laxante sin efectos } \\
\text { adversos relevantes e incluso en gestantes de } \\
\text { alto riesgo. Su uso durante el primer trimestre } \\
\text { queda a criterio medico, quien debe determinar } \\
\text { la conveniencia de su administración. Puede ser } \\
\text { usado libremente en madres que estén } \\
\text { amamantando. }\end{array}$ & $\begin{array}{l}\text { Revista de } \\
\text { fitoterapia. 2004; }\end{array}$ \\
\hline $\begin{array}{ll}\text { Los parámetros } & \text { de } \\
\text { seguridad } & \text { en } \\
\text { Fitoterapia. } & \end{array}$ & Martínez Guijarro J. & Rev. & $\begin{array}{l}\text { No evidencia de riesgo de malformaciones al } \\
\text { administrarse la Cáscara sagrada en el primer } \\
\text { trimestre del embarazo, aun asi se engloba en la } \\
\text { categoría C y se debe evitar su uso durante el } \\
\text { primer trimestre del embarazo, porel riesgo de } \\
\text { genotoxicidad de varios derivados antracénicos. } \\
\text { Durante la lactancia, se aconseja evitarlo, por un } \\
\text { aumento de diarreas en lactantes. }\end{array}$ & $\begin{array}{l}\text { Revista de } \\
\text { Fitoterapia. } 2005\end{array}$ \\
\hline $\begin{array}{ll}\text { Los parámetros } & \text { de } \\
\text { seguridad } & \text { en } \\
\text { Fitoterapia. } & \\
\end{array}$ & Martínez Guijarro J. & Rev. & $\begin{array}{l}\text { No existe ninguna limitación de uso de las } \\
\text { semillas de plantago en embarazo y lactancia. }\end{array}$ & $\begin{array}{l}\text { Revista de } \\
\text { Fitoterapia. } 2005\end{array}$ \\
\hline $\begin{array}{l}\text { Las flores de Bach en } \\
\text { obstetricia. }\end{array}$ & Muñoz-Sellés & Rev. & $\begin{array}{l}\text { Las flores de Bach dice que son una terapia } \\
\text { vibracional, Se pueden administrar a las mujeres } \\
\text { durante el embarazo, parto y puerperio, } \\
\text { también a su entorno familiar y a los } \\
\text { profesionales de lasalud quetrabajamos junto a } \\
\text { ellas. }\end{array}$ & $\begin{array}{l}\text { E. Matronas Prof. } \\
2007\end{array}$ \\
\hline $\begin{array}{l}\text { Medicamentos, } \\
\text { enfermedades y } \\
\text { lactancia, una ayuda en } \\
\text { español en Internet: } \\
\text { www.e-lactancia.org. }\end{array}$ & Paricio JM. & Rev. & $\begin{array}{l}\text { El gran contenido en flavonoides de muchas } \\
\text { plantas, por su potente actividad estrogénica } \\
\text { puede frenar la lactancia; el uso crónico o abuso } \\
\text { de plantas con pretendidas propiedades } \\
\text { galactogogas (alcachofa, anís, comino, cimifuga, } \\
\text { efedra, ginseng, lino, lúpulo, regaliz, romero o } \\
\text { zarzaparrilla) pueden disminuirla producción de } \\
\text { leche- }\end{array}$ & $\begin{array}{l}\text { AEPap ed. Curso de } \\
\text { Actualización } \\
\text { Pediatría. Madrid: } \\
\text { Exlibris Ediciones; }\end{array}$ \\
\hline $\begin{array}{l}\text { Lactancia materna: guía } \\
\text { para profesionales. } \\
\text { Comité de Lactancia } \\
\text { Materna de la } \\
\text { Asociación Española de } \\
\text { Pediatría. }\end{array}$ & Martín J. & Rev. & $\begin{array}{l}\text { Los remedios más extendidos para favorecer la } \\
\text { producción de leche son la almendra cruda, la } \\
\text { cerveza, la horchata y la infusión de hinojo. La } \\
\text { infusión de hinojo con malta y anís verde y los } \\
\text { comprimidos de alfalfa tienen gran aceptación. }\end{array}$ & $\begin{array}{l}\text { Monográficas de la } \\
\text { A.E.P. no 5. Madrid: } \\
\text { Ergon; } 2004 \text {. }\end{array}$ \\
\hline
\end{tabular}

\section{RESULTADOS}

El uso de plantas medicinales en el embarazo es extremadamente habitual. Según el artículo, Consumo de plantas medicinales por mujeres embarazadas, publicado por Macías-Peacok B. y colaboradores en el 2009, se estima que hasta un $55 \%$ de las mujeres embarazas las utilizan, encontrándose el jengibre y la equinácea entre las más utilizadas. Sin embargo, a pesar de que las mujeres reconocen el riesgo potencial del uso de 
medicamentos durante el embarazo, parecen no ser conscientes de que los componentes de las plantas pueden interactuar con medicamentos prescriptos y algunos incluso causar malformaciones en el feto o ser abortivos.

En cuanto a la etapa del embarazo de mayor consumo, se identifica que es el primer trimestre de la gestación donde las mujeres consumen la mayor cantidad de preparados de las plantas medicinales. Se identifica que el mayor porcentaje de las gestantes utiliza las plantas sin indicación médica, ya que el uso está fundamentado en el conocimiento tradicional, sin embargo, un número importante de personal médico prescribe el consumo de las mismas ${ }^{14}$.

La equinácea es una de las plantas más efectivas frente a numerosos virus y bacterias responsables de infecciones. Eficaz para el refriado común e infecciones vaginales por levaduras. Entre 1996 y 1998, 206 mujeres contactaron con el servicio canadiense Motherisk, de Canadá, por haber tomado equinácea durante el embarazo (112 mujeres la usaron durante el primer trimestre). No se detectaron diferencias significativas de mayor riesgo para el embarazo comparando a este grupo con un grupo control, pero por el limitado tamaño de la muestra y por la falta de estudios adicionales debería evitarse su uso sin indicación médica ${ }^{15}$. Además, aunque no se ha demostrado teratogenicidad, otro estudio sugiere que la equinácea podría afectar el desarrollo fetal en humanos al interferir con la angiogénesis embrional, y por ello no debería recomendarse su uso en mujeres embarazadas. Tampoco debe usarse durante la lactancia sin indicación médica ${ }^{16}$.

El arándano americano o arándano rojo reduce la frecuencia de infecciones urinarias al evitar la adherencia de E. coli y otras bacterias al epitelio urinario. El arándano rojo y el jugo de arándano rojo es seguro de consumir durante el embarazo y la lactancia. Pero no se debe usar suplementos dietéticos que contienen productos de arándano rojo. No se sabe si estos son seguros durante el embarazo y la lactancia ${ }^{17}$.

La raíz de jengibre posee actividad antiemética debido a su acción anticolinérgica y antihistamínica. Es una planta muy utilizada, especialmente 
en la medicinal tradicional china, para tratar las náuseas en mujeres embarazadas (la Real Farmacopea China no señala ninguna contraindicación para el embarazo). Algunos estudios muestran mejoras en la intensidad de las náuseas y vómitos en las mujeres embarazadas comparado con un placebo y no hay evidencias de que las dosis terapéuticas para la actividad ( 1 g de raíz desecada) produzcan daños ni al feto ni a la madre ${ }^{18,19}$. Sin embargo, la Comisión E contraindica su consumo durante el embarazo, probablemente debido a que uno de sus componentes (6-gingerol) administrado de forma aislada y en dosis altas tiene actividad mutagénica in vitro, a pesar de que se ha demostrado la actividad antimutagénica de otros componentes de esta planta. Por la falta de estudios tampoco se aconseja su consumo durante la lactancia ${ }^{20}$.

La ipecacuana se utiliza para hacer jarabe de ipecacuana, un emético muy efectivo. Aplicable a lactantes, niños, embarazadas y adultos mayores, en dependencia del cuadro sintomático existente. Existen estudios como el realizado por Parada López $\mathrm{N}$. en el que se vio que al administrar a las gestantes que presentaban un cuadro de hiperémesis gravídica, 30 minutos antes del desayuno, 1 a 3 gotas de jarabe de ipecacuana durante 2 semanas, que en la primera semana continuaron los vómitos en más de un tercio de las gestantes, pero ya en la segunda semana se produjo una sustancial mejora del 93,5\% de las gestantes ${ }^{21}$. Por tanto, podemos decir que el jarabe de ipecacuana es efectivo para tratar ese molesto trastorno en las embarazadas y puede utilizarse como medicina alternativa para sustituir productos farmacéuticos de elaboración industrial.

Las partes aéreas de la hierba de San Juan se utilizan para tratar la depresión postparto leve a moderada, incluyendo los síntomas asociados a premenopausia o menopausia, aunque su valor para la depresión grave no está demostrado. En 2009, un estudio prospectivo controlado de 54 mujeres que contactaron con el servicio canadiense Motherisk por haber consumido esta planta durante el embarazo no mostró diferencias significativas, en cuanto a las malformaciones en el feto, comparándolas con un grupo control que no 
había consumido la planta. Sin embargo, por la falta de estudios la ESCOP no aconseja su uso durante la lactancia ni el embarazo sin indicación médica ${ }^{22}$.

La raíz de Valeriana se utiliza para tratar el nerviosismo y la dificultad ocasional para conciliar el sueño. Los componentes activos de la planta, los valepotriatos, no parece que produzcan fetotoxicidad, sin embargo, en un estudio llevado a cabo en ratas, en dosis elevadas, apareció un ligero retraso en la osificación y en otro estudio in vitro presentó cierto potencial mutagénico y citotóxico. Se ignora si los componentes de esta planta son excretados en cantidades significativas con la leche materna, y si ello pudiese afectar al niño, aunque, en general, el uso de sedantes está desaconsejado debido al posible aumento del riesgo de muerte súbita. Por la falta de estudios no debería usarse durante el embarazo y lactancia sin indicación médica y solo se acepta su uso en caso de ausencia de alternativas terapéuticas más seguras bajo prescripción y control médico ${ }^{17}$.

En algunos países, el uso del aceite de onagra en las últimas semanas de gestación para inducir el parto es extremadamente habitual. No se han notificado eventos adversos en el feto, pero se desconocen los efectos cuando se usa con otros fines o en otras etapas del embarazo, por lo que solo debe usarse por indicación médica. La administración a madres lactantes durante 8 meses, empezando en los meses 2 a 6 de la lactancia, condujo a una mayor concentración de ácidos grasos esenciales en las mujeres frente al grupo control, sin que se notificaran efectos adversos ni en la madre ni en el lactante ${ }^{17}$.

Dada la importancia que tiene el estreñimiento en el embarazo, puerperio y lactancia, resulta importante valorar el uso de laxantes en estas condiciones. EI SEN y sus hojas le confieren una acción laxante a dosis bajas y purgante a dosis mayores. El efecto se produce tras un periodo de latencia de 8-10 h. EI SEN ha sido señalado como seguro en el $2 \circ$ y 30 trimestre de embarazo, y se ha visto que en esta etapa, los beneficios superan en gran medida a los riesgos ${ }^{23}$. En una revisión realizada por Morales M.A. se ha visto 
que el SEN tiene un buen efecto laxante sin efectos adversos relevantes e incluso en gestantes de alto riesgo. Existen suficientes estudios que dan prueba de la seguridad y eficacia del uso durante el embarazo y puerperio. Su uso durante el primer trimestre queda a criterio medico, quien debe determinar la conveniencia de su administración. Puede ser usado libremente en madres que estén amamantando, ya que no presenta efectos laxantes o nocivos en el lactante ${ }^{24}$.

La Cáscara sagrada tiene actividad laxante estimulante. Un estudio prospectivo realizado sobre 53 mujeres no evidenció riesgo de malformaciones al administrarse en el primer trimestre del embarazo, aun así se engloba en la categoría C y se debe evitar su uso durante el primer trimestre del embarazo, por el riesgo de genotoxicidad de varios derivados antracénicos. Durante la lactancia, algunas fuentes lo consideran compatible, si bien otras aconsejan evitarlo, pues aparecen trazas de antraquinonas en leche materna y se sugiere un aumento de incidencia de diarreas en lactantes ${ }^{23}$.

Las semillas de plantago contienen un elevado porcentaje de fibra, por lo que se utilizan como laxante mecánico o formador de masa. No existe ninguna limitación de uso en embarazo y lactancia, puesto que los componentes de las semillas no se absorben y no ejercen efectos sistémicos ${ }^{22}$.

Una revisión elaborada por la matrona Muñoz Selles sobre las flores de Bach dice que son una terapia vibracional, que está en auge en nuestro país. Son una herramienta de medicina holística que se puede utilizar en muchas situaciones, sin embargo, no se ha encontrado evidencia científica que demuestre que su efecto es exclusivamente el de un placebo. No presentan efectos secundarios y son fáciles de proporcionar. Se pueden administrar a las mujeres durante el embarazo, parto y puerperio, también a su entorno familiar y a los profesionales de la salud que trabajamos junto a ellas ${ }^{25}$.

El gran contenido en flavonoides de muchas plantas, por su potente actividad estrogénica puede frenar la lactancia; el uso crónico o abuso de 
plantas con pretendidas propiedades galactogogas (alcachofa, anís, comino, cimifuga, efedra, ginseng, lino, lúpulo, regaliz, romero o zarzaparrilla) pueden disminuir la producción de leche ${ }^{25}$. En España los remedios más extendidos para favorecer la producción de leche son la almendra cruda, la cerveza, la horchata y la infusión de hinojo. La infusión de hinojo con malta y anís verde y los comprimidos de alfalfa tienen gran aceptación ${ }^{27}$.

Una revisión realizada por Romano Santos sobre los galactógogos, del listado mostrado a continuación de plantas expuestas como galactogogas, no disponemos en la actualidad de estudios rigurosos que avalen su eficacia y seguridad ${ }^{28}$ (Tabla 3)

TABLA 3.- Nivel de riesgo sobre galactogogos.

\begin{tabular}{|c|c|c|}
\hline PLANTA & NIVEL DE RIESGO & CONTRAINDICACIONES \\
\hline $\begin{array}{l}\text { Albahaca } \\
\text { Ocimum basilicum }\end{array}$ & Sin clasificar & $\begin{array}{l}\text { No utilizar el aceite esencial por vía interna en el } \\
\text { embarazo y la lactancia }\end{array}$ \\
\hline \begin{tabular}{|l|} 
Alcaravea \\
Carum carvi \\
\end{tabular} & Sin clasificar & $\begin{array}{l}\text { Embarazo y lactancia: no hay datos; se aconseja } \\
\text { no utilizar sin autorización médica }\end{array}$ \\
\hline $\begin{array}{l}\text { Anís } \\
\text { Pimpinella anisum }\end{array}$ & $\begin{array}{l}\text { Riesgo } 2 \\
\text { Puede disminuir la producción de } \\
\text { leche }\end{array}$ & $\begin{array}{l}\text { No utilizar el aceite esencial por vía interna en } \\
\text { el embarazoy la lactancia }\end{array}$ \\
\hline $\begin{array}{l}\text { Cardo mariano } \\
\text { Silybum marianum }\end{array}$ & $\begin{array}{l}\text { Riesgo } 0 \\
\text { No se han demostrado efectos } \\
\text { galactogogos }\end{array}$ & $\begin{array}{l}\text { Embarazo y lactancia: no hay datos; se aconseja } \\
\text { no utilizar sin autorización médica }\end{array}$ \\
\hline $\begin{array}{l}\text { Comino } \\
\text { Cuminum cyminum }\end{array}$ & $\begin{array}{l}\text { Riesgo } 2 \\
\text { Puede disminuir la producción de } \\
\text { leche }\end{array}$ & $\begin{array}{l}\text { Embarazo y lactancia: no hay datos; se aconseja } \\
\text { no utilizar }\end{array}$ \\
\hline \begin{tabular}{|l|} 
Eneldo \\
Anethum graveolens
\end{tabular} & Sin clasificar & - \\
\hline $\begin{array}{l}\text { Fenogreco } \\
\text { Trigonella foenum-graecum }\end{array}$ & $\begin{array}{l}\text { Riesgo } 1 \\
\text { No se han demostrado efectos } \\
\text { galactogogos }\end{array}$ & $\begin{array}{l}\text { Embarazo y lactancia: no hay datos; se aconseja } \\
\text { no utilizar }\end{array}$ \\
\hline \begin{tabular}{|l|} 
Galega \\
Galega officinalis
\end{tabular} & Sin clasificar & Contraindicado en el embarazo y la lactancia \\
\hline $\begin{array}{l}\text { Hinojo } \\
\text { Foeniculum vulgare }\end{array}$ & $\begin{array}{l}\text { Riesgo } 2 \\
\text { Puede disminuir la producción de } \\
\text { leche }\end{array}$ & $\begin{array}{l}\text { Embarazo y lactancia: no hay datos; se aconseja } \\
\text { no utilizar }\end{array}$ \\
\hline \begin{tabular}{|l|} 
Ortiga menor \\
Urtica urens
\end{tabular} & Sin clasificar & $\begin{array}{l}\text { Embarazo y lactancia: no hay datos; se aconseja } \\
\text { no utilizar }\end{array}$ \\
\hline \begin{tabular}{|l} 
Rapónchigo \\
Campanula rapunculus
\end{tabular} & Sin clasificar & - \\
\hline \begin{tabular}{|l|} 
Sauzgatillo \\
Vitex agnus-castus
\end{tabular} & Riesgo 3 & Contraindicado en el embarazoy la lactancia \\
\hline
\end{tabular}




\section{SCUSI ÓN Y CONCLUSIONES}

De forma general las mujeres no están educadas en cuanto a la influencia que ejerce el estilo de vida en las primeras células embrionarias, específicamente el consumo no racionalizado de plantas medicinales en forma de infusiones, decocciones, etcétera; por lo que es de vital importancia aportar los conocimientos necesarios para que se modifique este hábito de riesgo durante el periodo de gestación y así evitar problemas con el bajo peso al nacer, malformaciones congénitas, parto pretérmino y otros trastornos relacionados.

Las gestantes consumen la mayor cantidad de preparados de las plantas medicinales durante el primer trimestre del embarazo, periodo donde el desarrollo del feto es más sensible a la influencia de factores ambientales, ya que entre el día 17 y 56 después de la fertilización tienen lugar los procesos de organización, diferenciación celular y organogénesis, y cualquier daño relacionado con fármacos, sustancias químicas, metabolitos de plantas medicinales o alguna enfermedad, puede afectar al desarrollo normal del feto, el cual puede ser más susceptible que los adultos a los efectos tóxicos por la exposición a estos factores del entorno, debido a una rápida división de las células, a la relativa falta de la detoxificación metabólica y de los mecanismos de excreción y al pobre funcionamiento del sistema inmune. Esto unido a las propiedades de los diferentes metabolitos activos, puede influir en la aparición de trastornos como la teratogénesis, citotoxicidad, genotoxicidad y otros.

Los productos fitoterápicos tienen márgenes terapeúticos más amplios y menos efectos secundarios que los sintéticos. Ello ha contribuido a la percepción en la población de que lo natural es igual a la inocuo. Sin embargo, la seguridad y eficacia del uso de las drogas vegetales debe ser demostrada mediante estudios científicos adecuados, con los mismos criterios que los utilizados para otros medicamentos. Mientras que la medicina convencional tiene como "patrón oro" el ensayo clínico aleatorizado, la medicina complementaria y alternativa, se basa en la experiencia clínica individual. 
Está muy extendida la creencia de que las plantas medicinales son seguras porque se han empleado desde tiempos muy antiguos y por el hecho de que son naturales, pero el uso continuado durante años o siglos no es una garantía de seguridad y lo natural no tiene por qué ser más seguro que los productos sintéticos.

Antes, durante y después del embarazo o lactancia materna las mujeres que desean tomar preparados herbarios, deben consultar con un profesional sanitario bien informado al respecto, porque muchos de los efectos de las plantas sobre los fetos y la leche materna son desconocidos.

Consideramos que la matrona y otros profesionales sanitarios relacionas con la salud materno-infantil tienen un papel crucial y que deben ofrecer más información sanitaria veraz y actualizada, ya que la mayoría de la referencias bibliográficas tienen su base en la tradición popular.

A pesar de los esfuerzos llevados a cabo por los grupos de trabajo a escala europea aún queda mucho camino por recorrer.

\section{BI BLI OGRAFí A}

1. Haya FJ. Uso práctico de la fitoterapia en ginecología. Madrid: Médica Panamericana; 2007.

2. Font Quer P. Plantas medicinales. El Dioscórides renovado. 7ạ ed. Barcelona: Península; 2005.

3. Scott CR, Jacobson H. A seleccion of international nutricional \& herbal remedies for breastfeeding concerns. Midwifery Today. 2005; (75): 38-9.

4. Escohotado A. Historia de las drogas 1. Madrid: Alianza; 1998.

5. Towler J, Bramall J. Comadronas en la historia y en la sociedad. Barcelona: Massonç; 1997.

6. Oliver MI. Plantas y remedios usados tradicionalmente en la asistencia al parto. Matronas Prof. 2000; 1: 32-41.

7. Montes M, Wilkomisrky T. Compendio de Fitoterapia. Concepción, Chile: Editorial Universidad de Concepción; 1996.

8. Weiss R. What is Phytotherapie? Zeitschrift für Phytotherapie. 1992; 13: 71-82. 
9. Bach E. Bach por Bach. Obras completas. Escritos florales. Buenos Aires: Continente; 1999.

10. Orozco R. Las flores de Bach hoy: una terapia en auge. Natura Medicatrix. 2003; 21: 300-9.

11. Tiran D. Euopean directives on nutricional supplements and herbal medicines: implications of midwifery practice. MIDIRS Midwifery Digest. 2003; 9(4): 176-81.

12. Martínez Guijarro J. Los parámetros de seguridad en Fitoterapia. Revista de Fitoterapia. 2005; 5 (2):117-133.

13. Generalitat Valenciana. Conselleria de Sanitat. Servicio de Pediatría del Hospital Marina Alta. Dènia, Alicante. (http://www.e-lactancia.org)

14. Macías-Peacok B, Pérez-Jackson L, Suárez-Crespo MF, FongDomínguez CO, Pupo-Perera E. Consumo de plantas medicinales por mujeres embarazadas. Rev Med Inst Mex Seguro Soc 2009; 47 (3): 331334.

15. Perri D, Dugoua JJ, Mills E, Koren G. Safety and efficacy of echinacea (Echinacea augustafolia, e. purpurea and e. pallida) during pregnancy and lactation. Can J Clin Pharmacol. 2006; 13: 262-7.

16. Chow $G$, et al. Dietary Echinacea purpurea during murine pregnancy: Effect on maternal hemopoiesis and fetal growth. Biol Neonate. 2006; 89: 133-138.

17. Albandoz $A$, et al. Uso de plantas medicinales en embarazo y lactancia. Argibideak 2003; 13(5): 29-34.

18. Bensky D, Barolet R. Chinese Herbal Medicine. Materia Medica. Seattle: Eastland Press; 1990.

19. Zhu CH. Clinical Handbook of Chinese Prepared Medicines. Brookline, Mass, Paradigm Publications; 1989.

20. Blumenthal M. The complete German Commission E monographs: therapeutic guide to herbal medicines. Integrative Medicine Communications. Germany: American Botanical Council; 1998.

21. Parada-López N, Martínez-Lora M, Hernández-Hernández L, Rodríguez-García LR. Efectividad de la ipecacuana en la hiperemesis gravídica. Medisan. 2002; 6(3):78-85. 
22. European Scientific Cooperative on Phytotherapy. ESCOP Monographs. 2a ed. Stuttgart, Germany: Exeter; 2003.

23. Anonimo. Risk assessment for Senna during pregnancy. Pharmacology. 1992; 44 (1): 20-22.

24. Morales MA, Díaz J, Barrientos C, Bachiller LI, Figueroa H. Uso del sen durante el embarazo y lactancia. Revista de fitoterapia. 2004; 4 (1): 41-51.

25. Muñoz-Sellés E. Las flores de Bach en obstetricia. Matronas Prof. 2007; 8 (2): 20-25.

26. Paricio JM. Medicamentos, enfermedades y lactancia, una ayuda en español en Internet: www.e-lactancia.org. En: AEPap ed. Curso de Actualización Pediatría. Madrid: Exlibris Ediciones; 2004: p.237-245.

27. Martín J. Lactancia materna: guía para profesionales. Comité de Lactancia Materna de la Asociación Española de Pediatría. Monográficas de la A.E.P. no 5. Madrid: Ergon; 2004.

28. Romano-Santos E, Fernández-González B, Díez-Soro I, MartínezBonafont S. ¿Qué sabemos de los galactogogos? Matronas Prof. 2009; 10 (4): 27-30. 